\title{
Analysis of the Impact of Climate Change on the Areas along the Sichuan-Tibet Railway
}

\author{
Siyuan Nie, Jie Ma* \\ School of Atmospheric Sciences, Chengdu University of Information Technology, Chengdu, China \\ Email: 2210635228@qq.com, ${ }^{\star} 961393820 @ q q . c o m$
}

How to cite this paper: Nie, S.Y. and Ma, J. (2021) Analysis of the Impact of Climate Change on the Areas along the Sichuan-Tibet Railway. Open Access Library Journal, 8: e7671.

https://doi.org/10.4236/oalib.1107671

Received: June 21, 2021

Accepted: July 24, 2021

Published: July 27, 2021

Copyright $\odot 2021$ by author(s) and Open Access Library Inc.

This work is licensed under the Creative Commons Attribution International License (CC BY 4.0).

http://creativecommons.org/licenses/by/4.0/

(c) (i) Open Access

\begin{abstract}
In order to further study the impact of climate change on the areas along the Sichuan-Tibet Railway, this paper uses the daily data set (V3.0) of China's surface climate data, and through various methods such as time division, correlation analysis, etc., the meteorological elements along the railway were analyzed in detail. Studies have shown that the precipitation in the areas along the Sichuan-Tibet Railway is mainly concentrated in summer. Autumn and winter are dry periods, and there is a high probability that it will not rain. From the precipitation anomaly, it can be analyzed that the probability of flooding and drought disasters along the Sichuan-Tibet Railway is very small. The average temperature increases with the age. The probability of extreme high temperature events in the study area is very small. The average annual wind speed has an upward trend throughout the four seasons. The average wind speed in spring is the largest, but the daily wind speed fluctuates little. There are no windy days, and the probability of strong winds in autumn and winter is $0.1 \%$. Relevant research results can provide scientific reference and basis for the construction of Sichuan-Tibet railway project.
\end{abstract}

\section{Subject Areas}

Atmospheric Science

\section{Keywords}

Climate Change, Sichuan-Tibet Railway, Precipitation, Temperature, Wind Direction and Speed

\section{Introduction}

\subsection{Research Background}

The Tibet Plateau is sparsely populated and has a harsh environment, but it plays a 
very important role in my country's strategic security. The construction of the Sichuan-Tibet Railway will further strengthen the channels of communication between the Qinghai-Tibet Plateau and the outside world. This is the need to promote national unity, maintain national unity, and consolidate border stability, and it is also a need to further promote the economic development of my country's southwestern region and Tibet [1].

For a long time, transportation and meteorology have been closely related, especially railways are highly sensitive industries for meteorological disasters. Due to the complex geological conditions along the Sichuan-Tibet Railway, severe geological disasters such as permafrost, high cold and hypoxia, avalanches, scattered areas, landslides, high-seismic areas, geothermal, and rock bursts, the SichuanTibet Railway has faced great challenges from the date of exploration. Among them, the climatic conditions along the Sichuan-Tibet Railway are very special, so climatic factors have a great impact on the selection of the Sichuan-Tibet Railway [2].

\subsection{Literature Review}

The high incidence areas of natural disasters on the Sichuan-Tibet Railway are mainly located in areas affected by the plateau monsoon. Research by Tang [3] showed that the establishment of the plateau monsoon destroyed the planetary air pressure belt and planetary wind system in the troposphere, resulting in the formation of various weather and climate characteristics in the plateau and surrounding areas; Xu's research [4] results show that in recent years The main body of the Qinghai-Tibet Plateau is getting warmer and wetter, but some areas on the east side of the plateau are getting warmer and drier, while the overall wind speed of the plateau is decreasing; the heating rate of different regions is different, and the central region is higher than the eastern region; the spatial distribution of precipitation is expressed In order to gradually decrease from the southeast to the northwest, and there have been many sudden changes. Zhang [5] pointed out that the eastern part of Sichuan-Tibet region should focus on preventing the effects of thunderstorms, short-term heavy rainfall, thunderstorms and gales; the central region should focus on preventing the effects of gale, daily temperature range, low temperature, frozen soil, etc.; the western region should focus on preventing strong winds and accumulations. Snow, daily temperature difference, low temperature, frozen soil, etc. The Sichuan-Tibet region is currently in a period of increasing wind speed on the climate background, and the risk is increasing, which requires attention. Duan's [6] research showed that global warming began to slow down in 1998, but the Qinghai-Tibet Plateau showed a trend of accelerating warming.

\subsection{The Purpose and Significance of the Research}

The Sichuan-Tibet Railway is a fast-track railway connecting Sichuan Province and the Tibet Autonomous Region in China. It runs east-west, starting from 
Chengdu in Sichuan Province in the east and Lhasa City in the Tibet Autonomous Region in the west. It is the second railway into Tibet in China and also in southwestern China. The Sichuan-Tibet Railway is located in the southern part of the Qinghai-Tibet Plateau. The construction project needs to face the construction problems of high mountains, high terrain, frequent earthquakes, complex geology, seasonal frozen soil, mountain disasters, plateau hypoxia, and ecological environmental protection. The Sichuan-Tibet Railway brings together a variety of extreme geographic environments and climatic characteristics such as mountains and heavy hills, high plateaus, windy sand deserts, thunder, rain, snow and frost, so it can be called "the most difficult railway to build." Therefore, studying the regional climate change and understanding the characteristics of regional climate change in recent decades will have important significance and value for the construction and development of the Sichuan-Tibet Railway. At the same time, these characteristics of climate change will provide a good theoretical support and scientific basis for the construction of plateau railways and the further understanding of climate change laws in its surrounding areas.

In the 2001 IPCC [7] report, it was pointed out that in the 21st century, global climate warming will be much more serious than in the 20th century, and the rate of temperature increase may be unprecedented in the past 1000 years. The impact of this globalization shows that research The impact of climate change on railways along the plateau area is not only of practical significance for the selection and construction of the Sichuan-Tibet Railway, but also of great significance for the future risk assessment of climate change on the Qinghai-Tibet Plateau and along the railway, and the maintenance and safe operation of the railway in the future.

\section{Research Data and Methods}

\subsection{Research Area Characteristics}

The area along the Sichuan-Tibet Railway starts from Chengdu City, Sichuan Province in the east through Pujiang, Ya'an, and Tianquan and then turns Erlang Mountain into the Ganzi Tibetan Autonomous Prefecture; after Kangding, Litang, and Baiyu, it crosses the Jinsha River and enters the Tibet Autonomous Region Qamdo; via Jiangda and Qamdo, Bangda, Basu, enter Nyingchi; pass Bomi and Nyingchi into Shannan area; after Sangri, Nedong, Gongga, west to Lhasa, Tibet Autonomous Region [8]. Select 5 stations located near the Sichuan-Tibet Railway as the main research Object.

The area along the Sichuan-Tibet Railway can be divided into two parts, the Tibet Plateau and the Sichuan Basin. The plateau area is low in air pressure, cold and dry, strong in sunlight, and long in sunshine. It is usually drier, colder, and wind speed higher than the low altitude area at the same latitude, but wetter, warmer, and wind speed is lower than the atmosphere at the same latitude and altitude. The Sichuan Basin is located in my country's inland area, affected by 
the monsoon climate, with sufficient water vapor, high relative humidity, humid climate, cloudy and foggy. Compared with areas at the same latitude, the annual average temperature is significantly higher, especially in winter. Because the cold air is blocked by the Qinling Daba Mountain in the north, the average winter temperature in the Sichuan Basin is much higher than that in the middle and lower reaches of the Yangtze River. The closed topography results in low wind speeds throughout the year in the Sichuan Basin. Spring droughts occur in the western region from April to May, and July to August is affected by the warm and humid southwest airflow and rainy.

\subsection{Research Data}

Due to the different time series of observation data of each element at each station along the Sichuan-Tibet Railway, based on the principle of not only considering the uniformity of the data and the length of the sequence, but also reflecting the facts of the four seasons of each element as much as possible, this article selects Linzhi, Bomi, Zuogong, and Li The cumulative precipitation, daily average temperature, daily maximum and daily minimum temperature, daily average wind speed, maximum wind speed, and daily average wind direction data at the five weather stations in Tang and Kangding from 2000 to 2019 from 20 to 20 Time series for autumn, winter and the whole year.

The materials cited in this article include:

1) China's ground climate data daily value data set (V3.0): 1951-2010 China's national ground station data corrected monthly report data file (A0/A1/A) basic data set, January 2011-The data for May 2012 is based on the monthly ground report data file (file A) reported by the provinces to the National Meteorological Information Center and the data from June to July 2012 is based on the real-time database data of the National Meteorological Information Center.

2) "Chinese Meteorological Disaster Grand Ceremony (Tibet Volume) (Sichuan Volume)", "Statistical Yearbook of Sichuan Province" and "Statistical Yearbook of Tibet Autonomous Region".

\subsection{Research Methods}

In this study, the study period is divided into four seasons, which are divided into spring (March-May), summer (June-August), autumn (September-November) and winter (December-February of the following year) [9]. The area along the Sichuan-Tibet Railway is divided into two areas, the Qinghai-Tibet Plateau and the Sichuan Basin. The Qinghai-Tibet Plateau area is selected from the Linzhi, Bo$\mathrm{mi}$ and Zuogong stations for research, and the Sichuan Basin area is selected for the Litang and Kangding stations.

In order to ensure the analysis of the precipitation in the four seasons and the continuity of the results, referring to past precipitation studies [10], different levels of precipitation are defined as: daily precipitation is $0.1 \leq$ precipitation $<10$ $\mathrm{mm}$ as light rain, and $10 \leq$ precipitation Rainfall $<25 \mathrm{~mm}$ means moderate rain, 
$25 \leq$ precipitation $<50 \mathrm{~mm}$ means heavy rain, and rainfall $\geq 50 \mathrm{~mm}$ means heavy rain.

There are many ways to divide drought and flood indicators. In the daily operations of meteorological departments, the percentage of precipitation anomaly is often used as an indicator to classify drought and flood. Different regions have different average precipitation in different periods. Therefore, it is a relative index with temporal and spatial contrast. Refer to this article [11], and the definition formula is:

$$
\begin{gathered}
P_{a}=\frac{P_{r}-\bar{P}_{r}}{\bar{P}_{r}} \times 100 \% \\
\bar{P}_{r}=\frac{1}{n} \sum_{i=1}^{n} P_{r i}
\end{gathered}
$$

In the equation: $P_{a}$ is the percentage of precipitation anomaly; $P_{\gamma}$ is the predicted precipitation, unitin $\mathrm{mm} ; \bar{P}_{\gamma}$ is the historical average precipitation in the same period, unit in $\mathrm{mm} ; n$ is the number of periods.

In order to better judge the degree of flooding in the area along the SichuanTibet Railway, taking into account the actual actual precipitation in this area, the research is only conducted by analyzing the precipitation data in summer in Litang area and the precipitation data in Zuogong area in winter. The specific levels of drought and flood are shown in Table 1 . No flood means that there will be no floods and droughts in the area. The drought and flood criteria in this paper are selected from literature [12], as shown in Table 1.

For the analysis of extreme temperature (Table 2), four indexes of summer days ( $\mathrm{SU}, \mathrm{d})$, extreme maximum temperature $\left(\mathrm{TXx},{ }^{\circ} \mathrm{C}\right)$, frost days $(\mathrm{FD}, \mathrm{d})$, and extreme minimum temperature $\left(\mathrm{TNn},{ }^{\circ} \mathrm{C}\right)$, are mainly selected by referring to the recent research [13].

According to the "Surface Meteorological Observation Regulations", winds with instantaneous wind speeds reaching or exceeding $17.0 \mathrm{~m} \cdot \mathrm{s}^{-1}$ (or visually estimated winds reaching or exceeding 8) are called gales. A gale appears on a certain day, which is called a gale day [14]. Table 3 shows wind direction and code.

Table 1. Drought and flood standard.

\begin{tabular}{ccc}
\hline Level & Anomaly percentage & Types of drought and flood \\
\hline 1 & $M \geq 75 \%$ & Particularly severe waterlogging \\
2 & $50 \% \leq M<75 \%$ & Flood \\
3 & $25 \% \leq M<50 \%$ & Partial waterlogging \\
4 & $-25 \%<M<25 \%$ & normal \\
5 & $-50 \%<M \leq-25 \%$ & Drought \\
6 & $-75 \%<M \leq-50 \%$ & Severe drought \\
7 & $M \leq-75 \%$ & Particularly severe drought \\
\hline
\end{tabular}


Table 2. Extreme temperature index.

\begin{tabular}{ccc}
\hline Index type & Index & Specific definition \\
\hline $\begin{array}{c}\text { Extreme high } \\
\text { temperature index }\end{array}$ & $\begin{array}{c}\text { Number of summer days } \\
(\mathrm{SU}, \mathrm{d})\end{array}$ & $\begin{array}{c}\text { All days of the year where the maximum } \\
\text { daily temperature is }>25^{\circ} \mathrm{C}\end{array}$ \\
temperature $\left(\mathrm{TXx},{ }^{\circ} \mathrm{C}\right)$ & $\begin{array}{c}\text { The maximum daily maximum } \\
\text { temperature during the year }\end{array}$ \\
$\begin{array}{c}\text { Extreme low } \\
\text { temperature index }\end{array}$ & $\begin{array}{c}\text { days }(\mathrm{FD}, \mathrm{d}) \\
\text { Extreme minimum } \\
\text { temperature }\left(\mathrm{TNn},{ }^{\circ} \mathrm{C}\right)\end{array}$ & $\begin{array}{c}\text { All days of the year where the lowest } \\
\text { daily temperature is less than } 0{ }^{\circ} \mathrm{C} \\
\text { The minimum daily minimum } \\
\text { temperature during the year }\end{array}$ \\
\hline
\end{tabular}

Table 3. Wind direction and corresponding number.

\begin{tabular}{cccccc}
\hline Wind direction & Code & Wind direction & Code & Wind direction & Code \\
\hline N & 1 & ENE & 4 & SE & 7 \\
NNE & 2 & E & 5 & SSE & 8 \\
NE & 3 & ESE & 6 & S & 9 \\
SSW & 10 & W & 13 & NNW & 16 \\
SW & 11 & WNW & 14 & C & 17 \\
WSW & 12 & NW & 15 & &
\end{tabular}

\section{Research Results}

\subsection{Analysis of Precipitation Characteristics}

The total precipitation in spring, summer, autumn and winter of five stations from 2000 to 2019 is calculated for analysis. The trend line of spring precipitation showed a downward trend, and the precipitation gap was very small $(<50$ $\mathrm{mm}$ ). The maximum precipitation is $531.6 \mathrm{~mm}$. The maximum precipitation in Zuogong is $117.7 \mathrm{~mm}$. (Figure 1) In the five regions, light rain days accounted for $40.5 \%$, of which Bomi light rain days accounted for $57.5 \%$, and Zuogong light rain days accounted for $24.3 \%$. The precipitation in summer is more consistent $(>200 \mathrm{~mm})$. The fluctuation range of the general trend line is small (decreasing), and the precipitation gap is less than $50 \mathrm{~mm}$. The precipitation in Litang area is too much, and the maximum precipitation can reach $602.8 \mathrm{~mm}$. However, the precipitation in Bomi area is relatively small, with the maximum of $553.9 \mathrm{~mm}$ and the minimum of $172.7 \mathrm{~mm}$. There are four rainstorm days, three in Linzhi and one in Bomi. Light rain days account for $55.7 \%$ and moderate rain days account for $12.8 \%$. In autumn, the precipitation in Zuogong and Litang area showed a downward trend, with less precipitation. Zuogong has the least precipitation, with the minimum value of $22.2 \mathrm{~mm}$. The number of days without precipitation is as high as $77.7 \%$, and light rain accounts for $20.1 \%$. In 


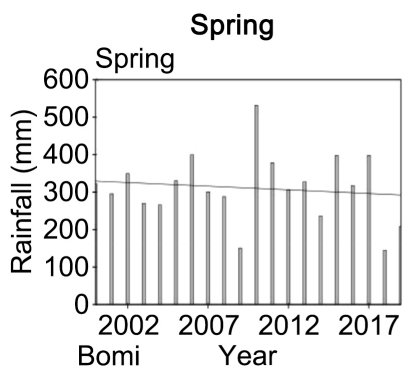

(a)

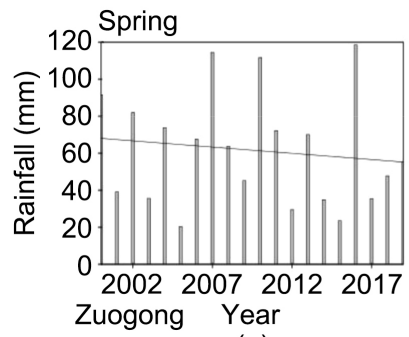

(e)

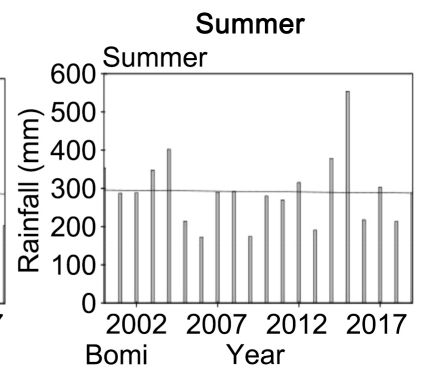

(b)

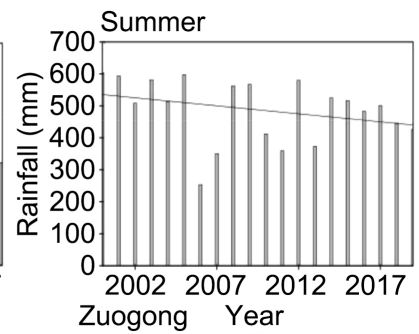

(f)

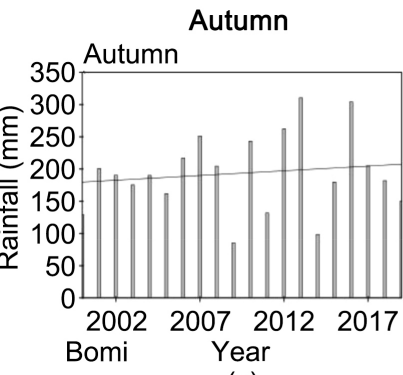

(c)

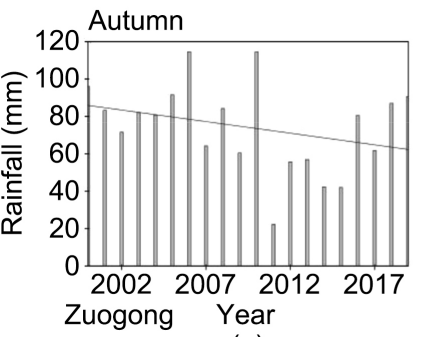

(g)

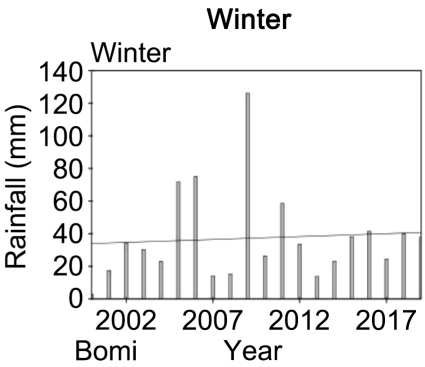

(d)

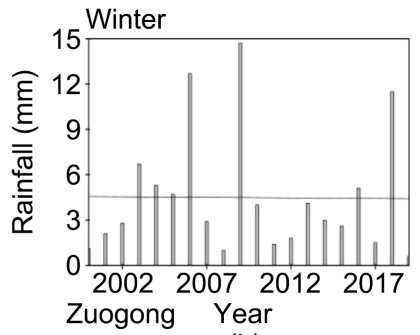

(h)

Figure 1. Observed from 2000 to 2019 (a) Bomi spring precipitation, (b) Bomi summer precipitation, (c) Bomi autumn precipitation, (d) Bomi winter precipitation, (e) Zuogong spring precipitation, (f) Litang Summer precipitation, (g) Zuogong autumn precipitation, (h) Zuogong winter precipitation.

the same year, the minimum precipitation in Litang was $99.9 \mathrm{~mm}$, with no precipitation days accounting for $64.2 \%$ and light rain for $30.6 \%$. In Linzhi, Bomi and Kangding, the fluctuation degree is larger $(>200 \mathrm{~mm})$. The maximum precipitation is $310.5 \mathrm{~mm}$. The light rain days accounted for $32.5 \%$, and the non rain days accounted for $62.1 \%$. The precipitation in winter is less consistent $(<130 \mathrm{~mm})$. The maximum precipitation is $126.1 \mathrm{~mm}$. The other four regions have low precipitation $(<20 \mathrm{~mm})$, and the proportion of days without rain is $88.7 \%$. No rain days in winter accounted for $87.7 \%$, which was the driest period in the four seasons.

Figure 2 is the interannual variation of precipitation in the five regions, with the largest precipitation in summer, the second in spring and autumn, and the least in winter. The average annual precipitation in Bomi is relatively high $(833.5 \mathrm{~mm})$, mainly in light rain, with few days of heavy rain and rainstorm. The average annual precipitation in Zuogong area is the least $(463.2 \mathrm{~mm})$, and the days without rain are the largest. July is the month with the most precipitation in the whole year, and the precipitation is relatively concentrated from July to September, and then gradually decreases. The summer precipitation in Litang area is the strongest (500 mm), but the light rain is still the main weather. After calculation, the precipitation anomaly in Litang is $12 \%$ in summer and $1.2 \%$ in Zuogong in winter, which are all within the normal range. Therefore, the possibility of drought and flood disasters along the Sichuan Tibet railway is very small. It is generally believed that the physical and chemical reactions between rainfall and the rock and soil of the slope cause changes in the material composition or structure and decrease in strength, which in turn affects the stability of the slope and is prone to landslide events [15]. According to statistics [16], the probability of landslide events in BomiLinzhi section is higher than that in other areas. There are four landslides, two of which are 


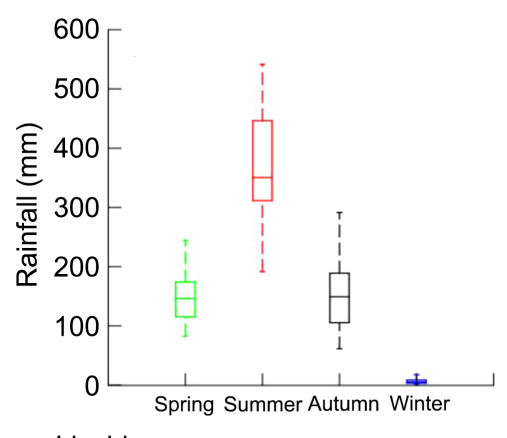

Linzhi

(a)

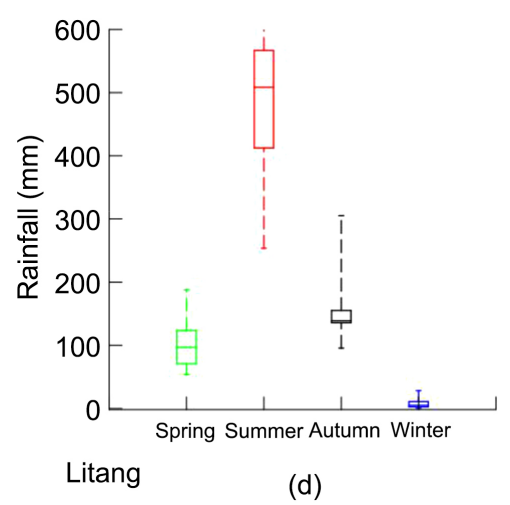

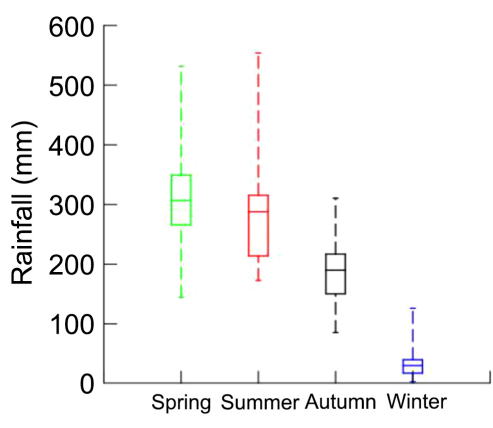

(b)

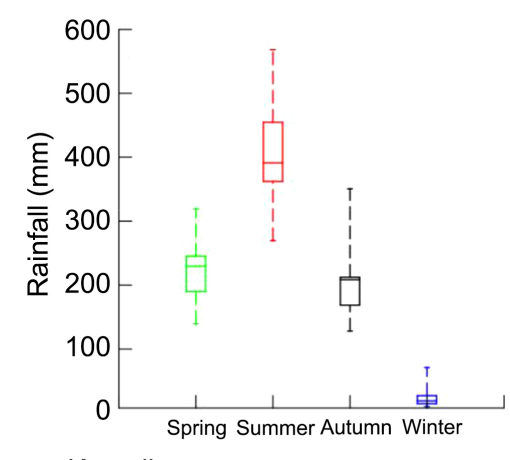

(e)

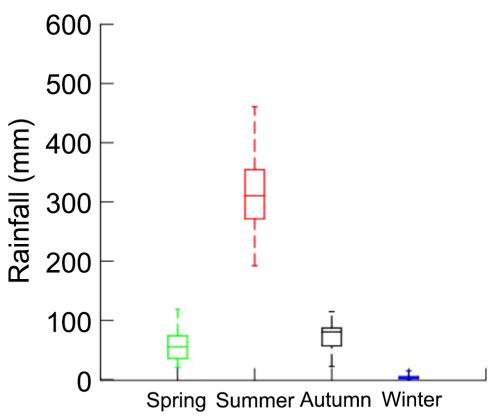

Zuogong

Figure 2. (a) Linzhi, (b) Bomi, (c) Zuogong, (d) Litang, (e) Kangding annual average precipitation observed from 2000 to 2019.

super large landslides. According to the distribution of disasters along the Sichuan Tibet railway, considering human economic activities, natural environment, geological environment and precipitation distribution [17], Linzhi and Bomi areas can be divided into low prone areas, while Zuogong, Litang and Kangding areas can be divided into non prone areas according to the days and duration of rainstorm.

\subsection{Analysis of Temperature Characteristics}

Figure 3 is observed average temperature from five station in 2000 to 2019. The overall average temperature in spring was lower $\left(<12^{\circ} \mathrm{C}\right)$. The average temperature in Linzhi is high $\left(11.25^{\circ} \mathrm{C}\right)$, and the daily maximum temperature is $28.4^{\circ} \mathrm{C}$. The average temperature in Zuogong is low $\left(5.12^{\circ} \mathrm{C}\right)$, and the daily minimum temperature is $-14.4^{\circ} \mathrm{C}$. The $\mathrm{Su}$ in spring was 97 days $(0.011 \%)$. The Su of Litang area is 0 , and Kangding area is the largest (41D); FD was 3043 days (0.33\%), and it was the largest in Litang area (1163d). The extreme maximum temperature is $30.1^{\circ} \mathrm{C}$ (Kangding), and the extreme minimum temperature is minus $16.8^{\circ} \mathrm{C}$ ( $\mathrm{Li}$ tang). The average temperature in summer is consistently higher $\left(>10^{\circ} \mathrm{C}\right)$. The fluctuation range of average temperature trend line is very small, and the temperature difference is very small $\left(<3^{\circ} \mathrm{C}\right)$. The highest temperature in Linzhi reached $31.4^{\circ} \mathrm{C}$ (July 2006), and the highest temperature in Bomi $\left(31.2^{\circ} \mathrm{C}\right)$. In summer, $\mathrm{Su}$ was $1293 \mathrm{~d}(0.14 \%)$. The Su of Litang area is the smallest $(3 \mathrm{D})$, and that of Linzhi Area is the largest (662d); FD is the least in summer (12 days), and most of them occur in Litang area. The extreme maximum temperature is $31.4^{\circ} \mathrm{C}$ (Linz- 
hi), and the extreme minimum temperature is minus $2.1^{\circ} \mathrm{C}$ (Litang). The overall average temperature in autumn is lower $\left(<11^{\circ} \mathrm{C}\right)$, and the average temperature in Zuogong and Litang is lower. The average temperature in Linzhi is higher $\left(10.2^{\circ} \mathrm{C}\right)$ than that in Litang $\left(5.05^{\circ} \mathrm{C}\right)$, which is slightly lower than that in spring. In autumn, the Su was 139 days $(0.015 \%)$. The Su value of Litang area is 0 , and that of Bomi area is the largest (93D); In autumn, the FD was 2852 days $(0.31 \%)$, and the largest in Zuogong and Litang. The extreme maximum temperature is $31.6^{\circ} \mathrm{C}$ (Kangding), and the extreme minimum temperature is $-19.7^{\circ} \mathrm{C}$ (Litang). In winter, the trend line of average temperature rises slowly, and the average temperature of five regions is consistently low. The average temperature in Zuogong is low (minus $3.3^{\circ} \mathrm{C}$ ), and the daily minimum temperature can reach minus $20.2^{\circ} \mathrm{C}$. $\mathrm{Su}$ was 0 in winter and FD was 8203 days in winter, accounting for $90.89 \%$. The extreme maximum temperature is $24.1^{\circ} \mathrm{C}$ (Kangding), and the extreme minimum temperature is minus $20.2^{\circ} \mathrm{C}$ (Zuogong).

The temperature of the five regions showed a warming trend, and the temperature in winter will be stronger than that in summer. The high temperature period of daily maximum temperature $\geq 30^{\circ} \mathrm{C}$ is mainly concentrated in Bomi area, which occurs from mid late July to early August. (Figure 4) The low temperature period with daily minimum temperature less than or equal to $-10^{\circ} \mathrm{C}$ is mainly concentrated in Zuogong and Litang areas, which occurs from the middle and late December to the early January of the next year. The low temperature period in Zuogong area lasts the longest. The most days in summer are in summer $(0.14 \%)$, and the probability of extreme low temperature events in winter is very high, with 90.89\% probability in frost period.

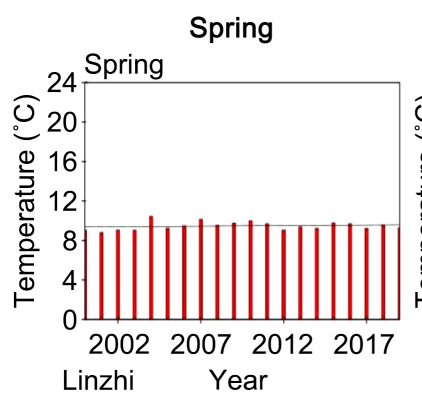

(a)

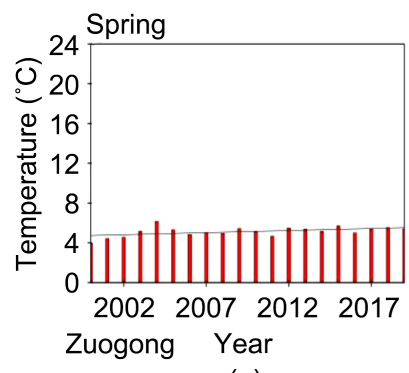

(e)

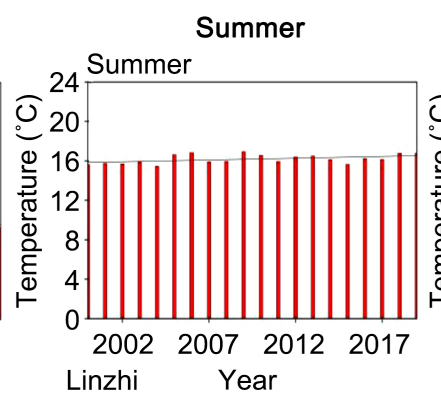

(b)

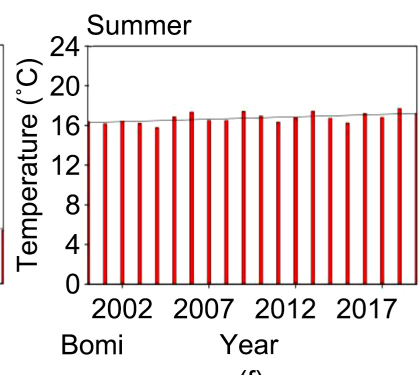

(f)

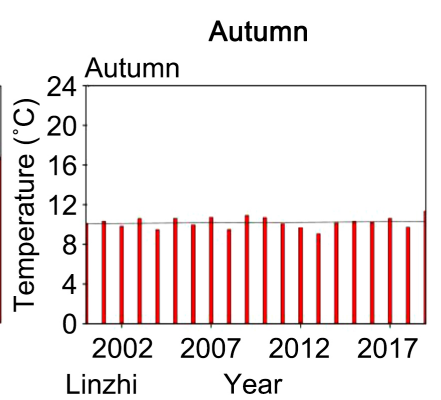

(c)

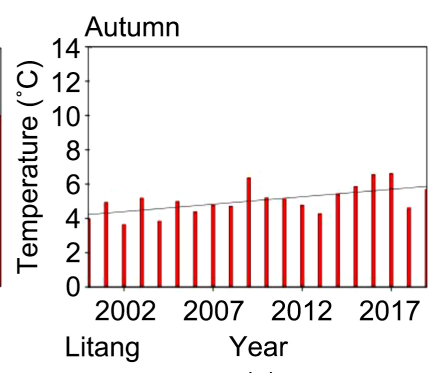

(g)

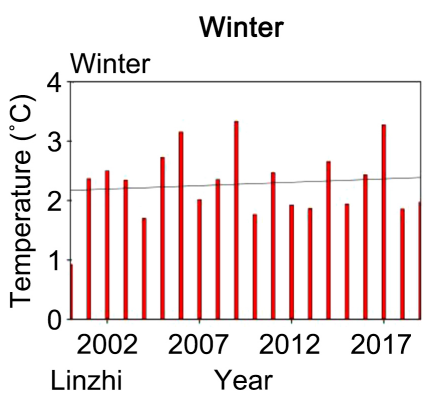

(d)

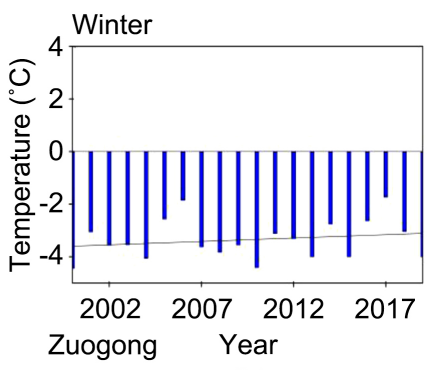

(h)

Figure 3. Observed from 2000 to 2019 (a) Lizhi spring average temperature, (b) Lizhi summer average temperature, (c) Lizhi autumn average temperature, (d) Lizhi winter average temperature, (e) Zuogong spring average temperature, (f) Bomi Summer average temperature, (g) Litang autumn average temperature, (h) Zuogong winter average temperature. 


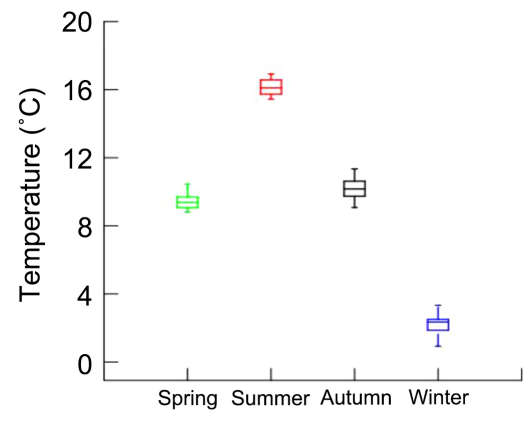
Linzhi

(a)

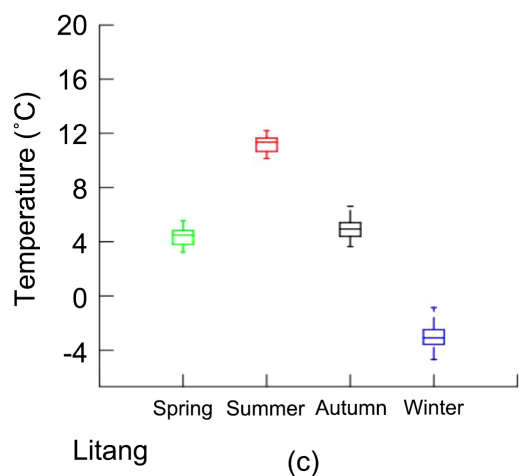

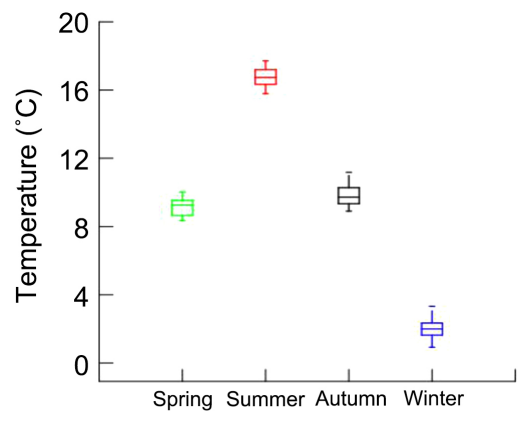

Bomi

(b)

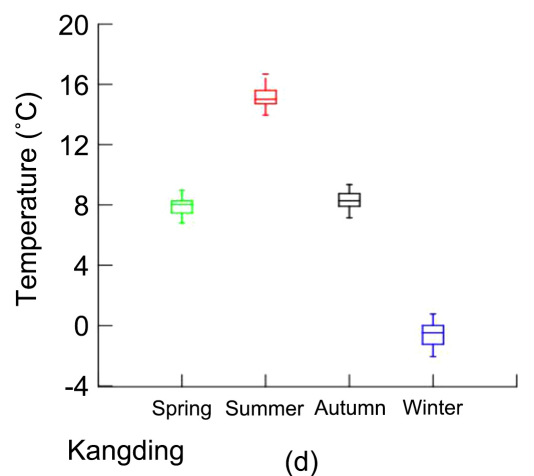

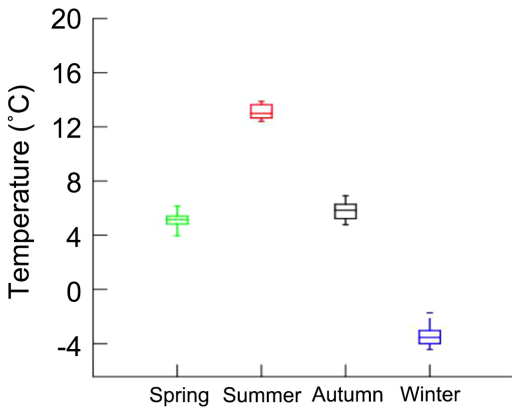

Zuogong

Figure 4. (a) Linzhi, (b) Bomi, (c) Zuogong, (d) Litang, (e) Kangding annual average temperature observed from 2000 to 2019.

\subsection{Analysis of Wind Speed Characteristics}

Figure 5 is observed average wind speed from five station in 2000 to 2019. Except for Linzhi Area, the trend line of average wind speed in spring is increasing year by year. The wind speed in Nyingchi fluctuates greatly, and the average wind speed is the lowest in $2013(0.31 \mathrm{~m} / \mathrm{s})$ and the highest in 19 years $(2.34$ $\mathrm{m} / \mathrm{s})$. The average wind speed in Zuogong area is low $(1.63 \mathrm{~m} / \mathrm{s})$, showing a weak upward trend with the annual growth $\left(0.044 \mathrm{~m} \cdot \mathrm{s}^{-1} / \mathrm{d}\right)$. The average wind speed in Kangding is the highest $(4.85 \mathrm{~m} / \mathrm{s})$, and the maximum wind speed appears in the late march of $2014(16.9 \mathrm{~m} / \mathrm{s})$. The average wind speed in summer is slightly lower than that in spring. As in spring, the average wind speed in Zuogong is the lowest $(1.22 \mathrm{~m} / \mathrm{s})$, the lowest wind speed is $0.7 \mathrm{~m} / \mathrm{s}$, and the maximum wind speed is $17.5 \mathrm{~m} / \mathrm{s}$. The average wind speed in Kangding is still the highest (2.51 $\mathrm{m} / \mathrm{s}$ ), but the maximum wind speed is only $15.7 \mathrm{~m} / \mathrm{s}$. There is only one day of gale in summer, which occurs in Zuogong area. The average wind speed trend line in autumn is the same as that in spring and summer, showing an upward trend $(<1 \mathrm{~m} / \mathrm{s})$. The average wind speed in autumn is low, and the average wind speed in Kangding is the largest $(2.51 \mathrm{~m} / \mathrm{s})$, and the maximum wind speed is 17.7 $\mathrm{m} / \mathrm{s}$. The average wind speed in other areas is between $1 \mathrm{~m} / \mathrm{s}$ and $1.5 \mathrm{~m} / \mathrm{s}$. The average wind speed in Zuogong is the lowest $(1.13 \mathrm{~m} / \mathrm{s})$, the days without wind is $0.1 \%$, and the maximum wind speed is $18 \mathrm{~m} / \mathrm{s}$. The gale days in autumn are only 2 days, which appear in Zuogong and Kangding areas. In winter, the average wind speed in Linzhi Area showed a slight downward trend, and the wind speed fluctuated greatly. Figure 6 is the annual average wind speed of the five regions 
from 2000 to 2019. The minimum wind speed was $1.18 \mathrm{~m} / \mathrm{s}$, and the maximum wind speed was $2.23 \mathrm{~m} / \mathrm{s}$. The average wind speed in Zuogong is low $(1.29 \mathrm{~m} / \mathrm{s})$, and the maximum wind speed is $18.0 \mathrm{~m} / \mathrm{s}$. The average wind speed in Kangding is the highest $(2.78 \mathrm{~m} / \mathrm{s})$, and the maximum wind speed appeared in $2002(17.0 \mathrm{~m} / \mathrm{s})$. The number of gale days in winter is the same as that in autumn, only 2 days.

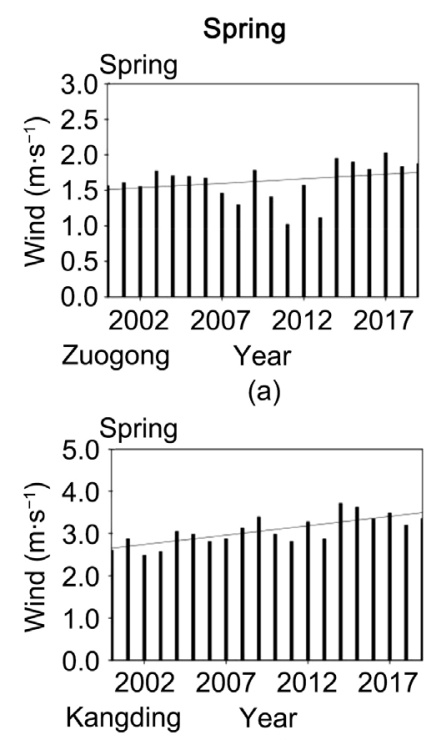

(e)

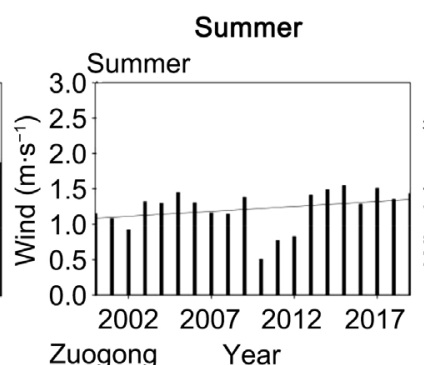

Zuogong Year

(b)

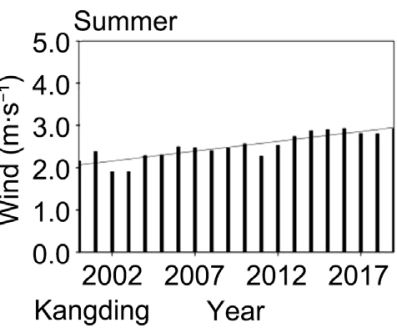

(f)

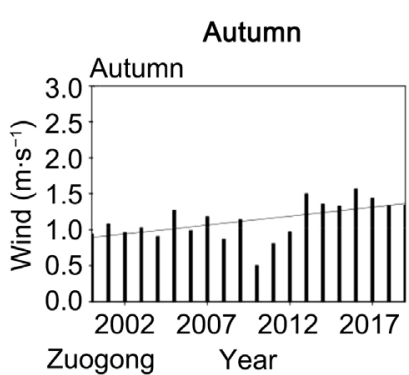

(c)

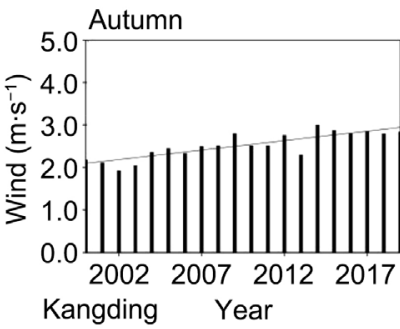

(g)

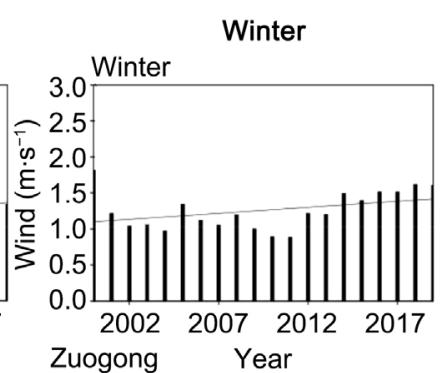

(d)

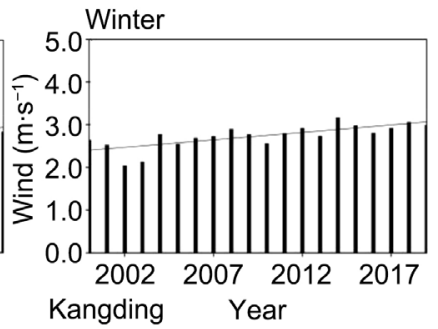

(h)

Figure 5. Observed from 2000 to 2019 (a) Zuogong spring average wind speed, (b) Zuogongsummer average wind speed, (c) Zuogong autumn average wind speed, (d) Zuogong winter average wind speed, (e) Kangding spring average wind speed, (f) Kangding Summer average wind speed, (g) Kangding autumn average wind speed, (h) Kangding winter average wind speed.

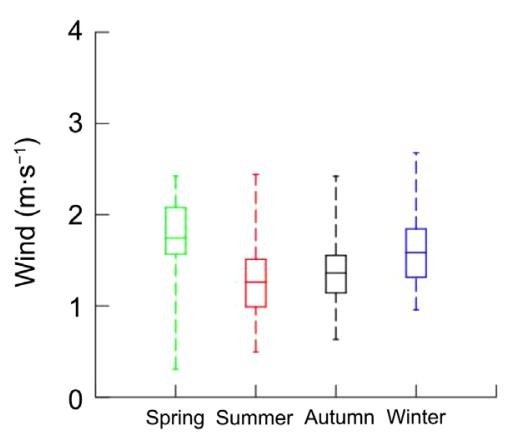

Linzhi

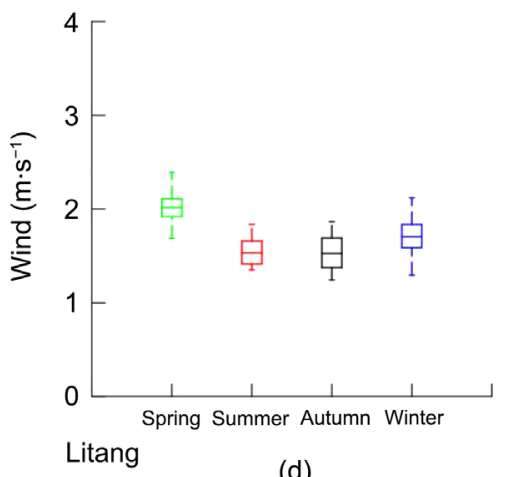

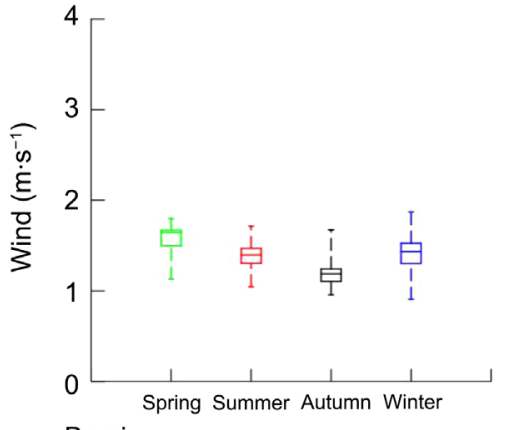

(b)

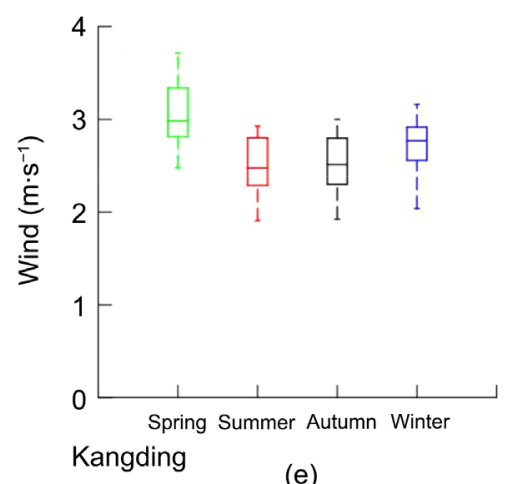

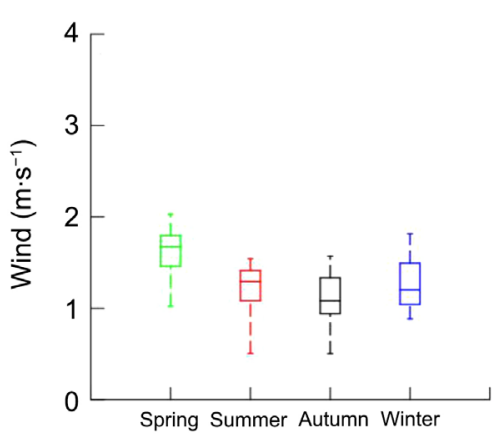

Zuogong

(c)

Figure 6. (a) Linzhi, (b) Bomi, (c) Zuogong, (d) Litang, (e) Kangding annual average wind speed observed from 2000 to 2019. 
In recent 20 years, the annual average wind speed in four seasons showed an increasing trend. The average wind speed in four seasons was the largest in spring, followed by winter, and similar and low in autumn and summer. Gales are most likely to occur in autumn and winter, but the probability is only $0.1 \%$. The daily average wind speed in Zuogong area fluctuates the most, and the probability of strong wind is slightly higher than the other four areas.

\subsection{Analysis of Wind Direction Characteristics}

Figure 7 is the wind direction characteristics of Linzhi and Bomi. The main trend of Linzhi Area is the east wind, the most frequent is positive east wind, followed by east to Southeast and east to northeast. The probability of maximum wind speed range above $6 \mathrm{~m} / \mathrm{s}$ is higher than the other three ranges. In winter, when the wind blows, the probability of wind speed greater than $6 \mathrm{~m} / \mathrm{s}$ is the highest, reaching $52.2 \%$. The main wind in the area of Bomi is southwest wind, followed by the wind in the south-west direction. The probability of maximum wind speed is more than $6 \mathrm{~m} / \mathrm{s}$, and the probability of wind speed greater than 6 $\mathrm{m} / \mathrm{s}$ is the highest in winter when the wind blows from west to south, reaching $63.4 \%$.

Figure 8 is the wind direction characteristics of Kangding and Zuogong. Zuogong area is mainly easterly wind. The probability of maximum wind speed above $6 \mathrm{~m} / \mathrm{s}$ in spring is high (46.8\%); The probability of maximum wind speed greater than $6 \mathrm{~m} / \mathrm{s}$ in summer is slightly greater than that of $5.5-6.0 \mathrm{~m} / \mathrm{s}$; In autumn, the probability of maximum wind speed in the easterly direction of 5.5 $6.0 \mathrm{~m} / \mathrm{s}$ increased significantly, reaching $44.2 \%$. The main wind direction in

Linzhi

ID: 56312
Bomi

ID: 56227

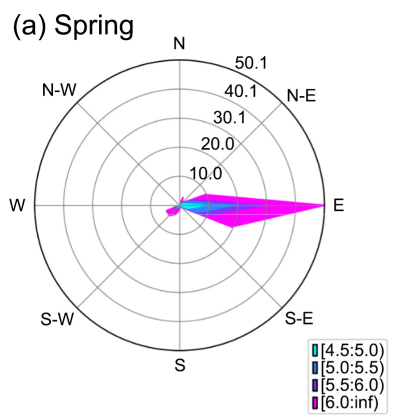

(b) Summer

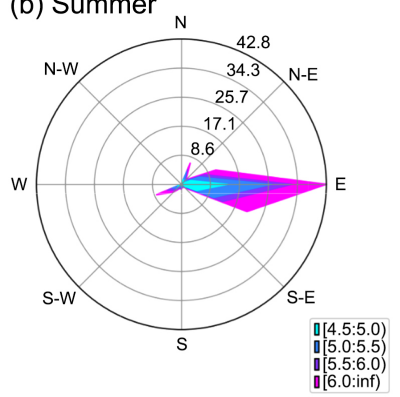

(a) Spring
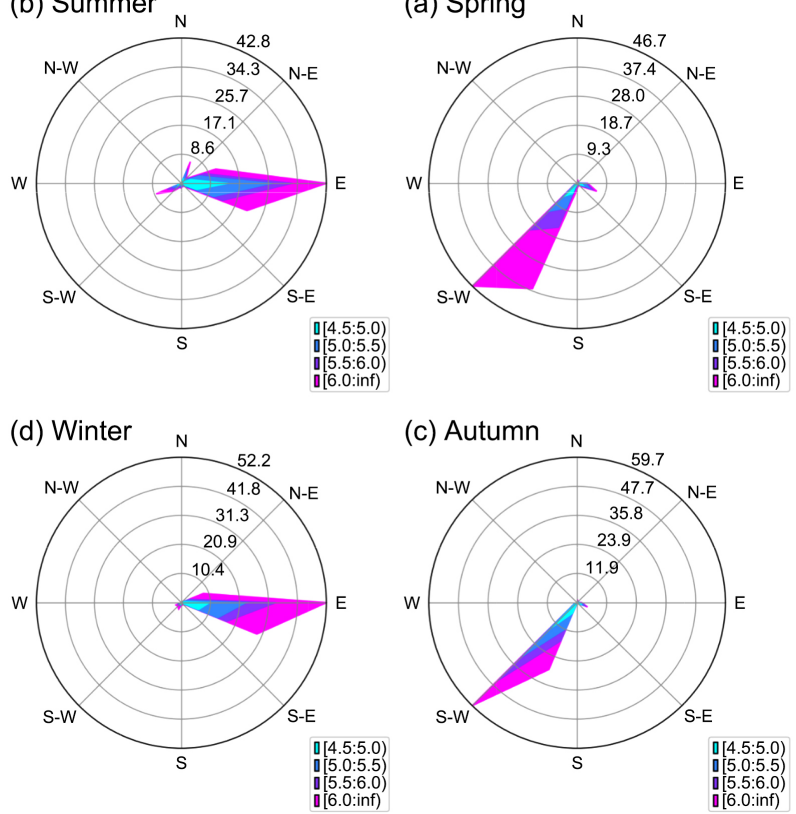

(c) Autumn

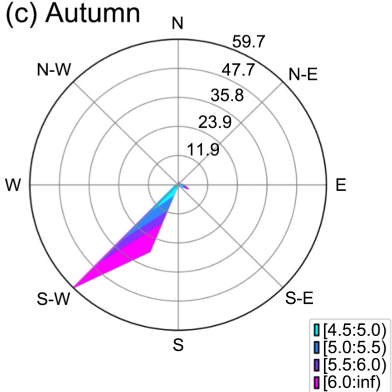

(b) Summer

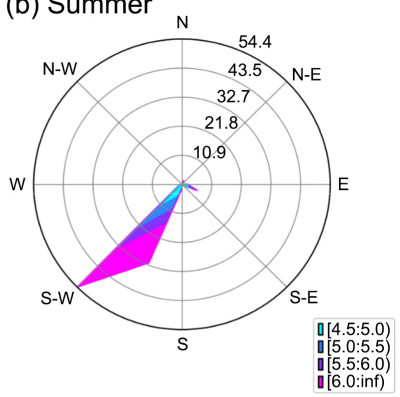

(d) Winter

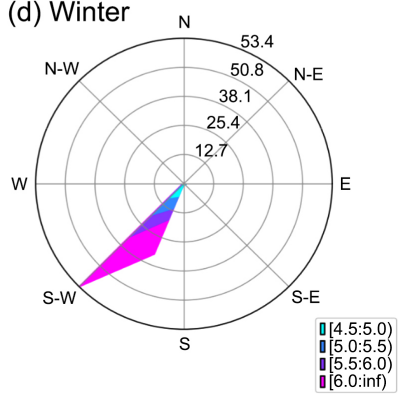

Figure 7. Wind direction characteristics of Linzhi and Bomi. 


\section{Zuogong}

ID: 56331

(a) Spring

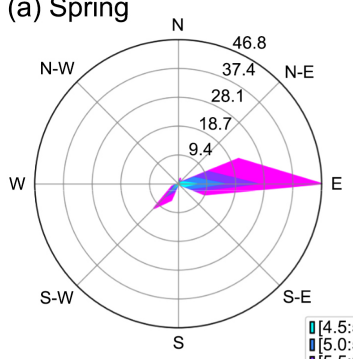

$0[4.5: 5.0)$
$\square[5.0: 5.5)$

0

(c) Autumn

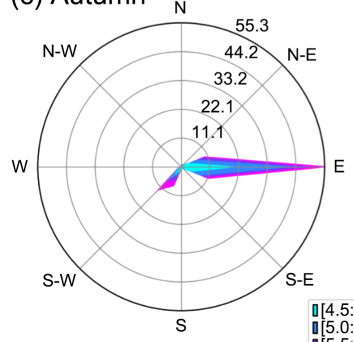

(b) Summer $\mathrm{N}$

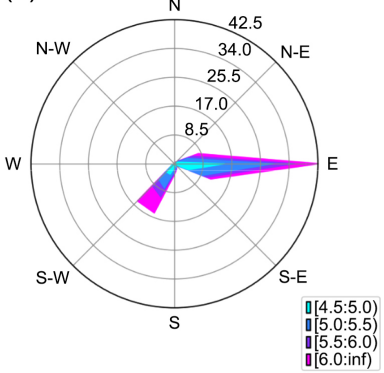

(d) Winter

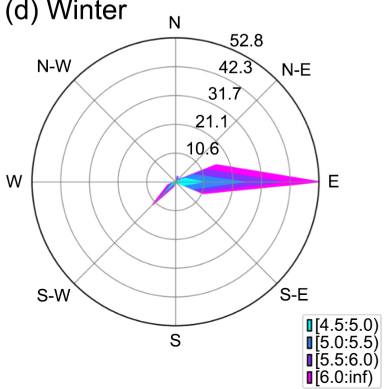

Kangding

ID: 56374
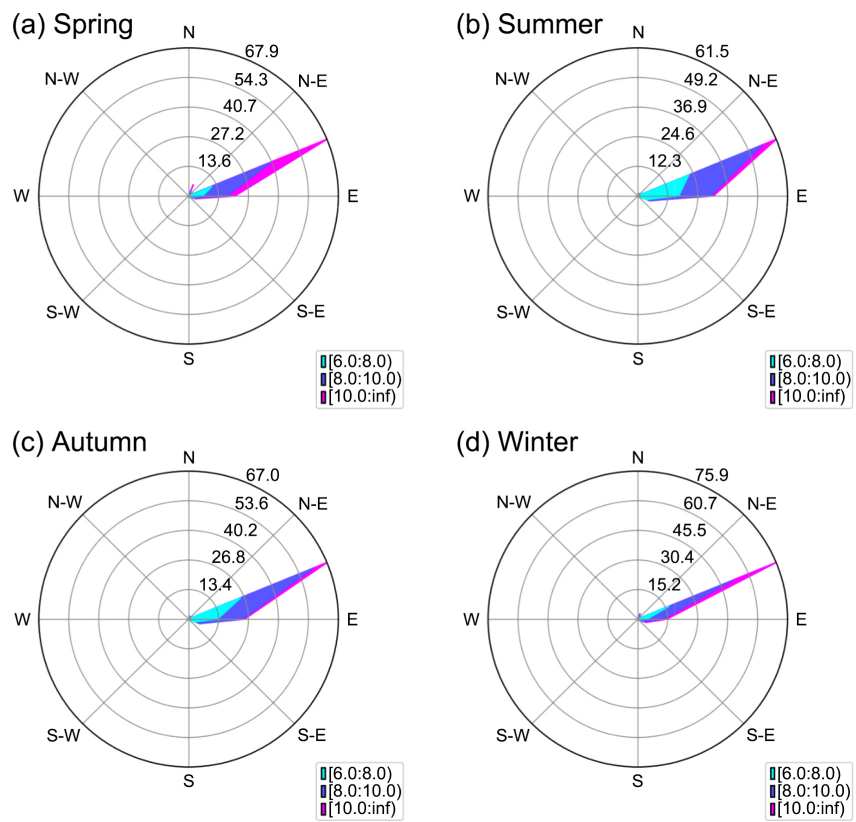

Figure 8. Wind direction characteristics of Kangding and Zuogong.

Litang

ID: 56331

(a) Spring

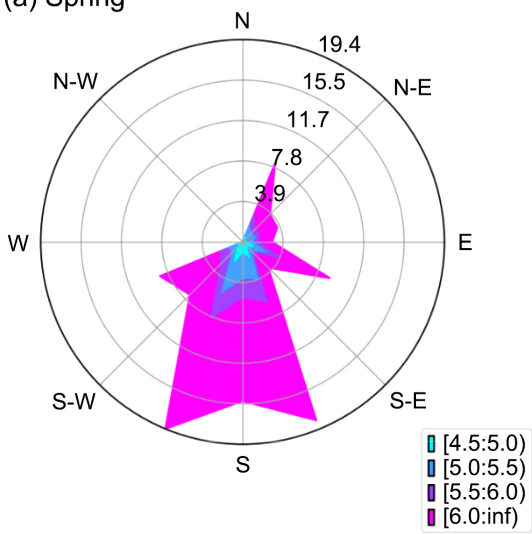

(c) Autumn

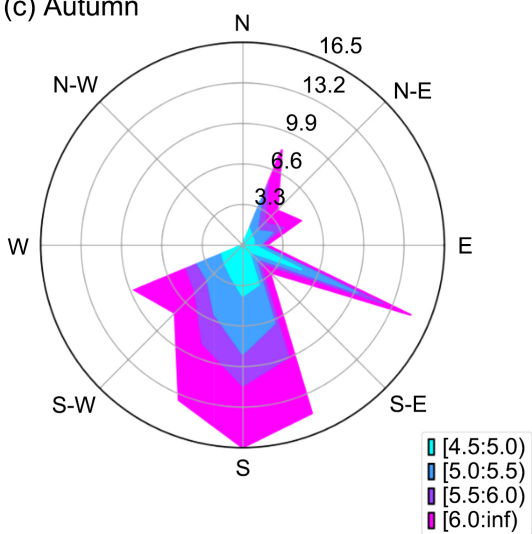

(b) Summer

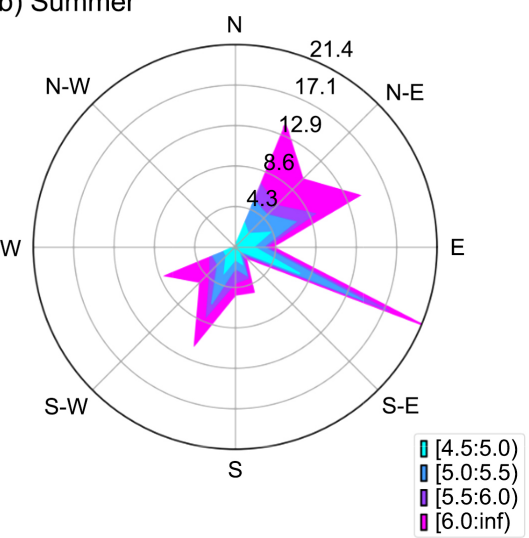

(d) Winter

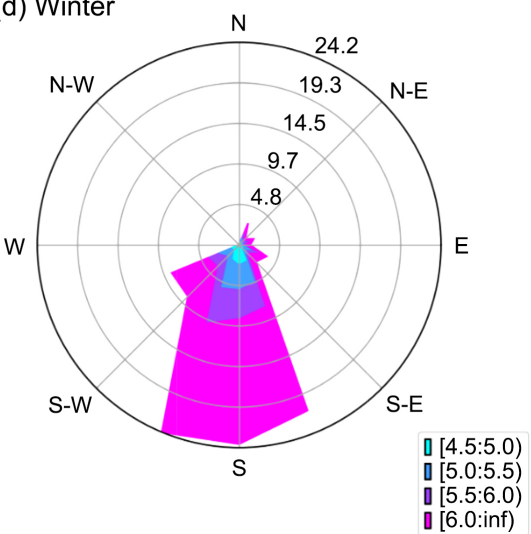

Figure 9. Wind direction characteristics of Litang. 
Kangding area is east northeast wind. The wind speed in Kangding is relatively high, and the probability that the maximum wind speed in spring is greater than $10.0 \mathrm{~m} / \mathrm{s}$ is significantly higher than the other two ranges (67.9\%); The probability that the maximum wind speed in summer and autumn is between $8.0 \mathrm{~m} / \mathrm{s}$ and $10.0 \mathrm{~m} / \mathrm{s}$ increases greatly; The probability of the maximum wind speed greater than $10.0 \mathrm{~m} / \mathrm{s}$ in winter reaches the maximum value $(75.9 \%)$ along the $\mathrm{Si}$ chuan Tibet railway.

Figure 9 is the wind direction characteristics of Litang. Litang area is mainly affected by southerly wind. In spring, the wind mainly blows south by Southwest and south by southeast; In summer, the frequency of east southeast wind is the highest; In autumn, the southerly wind is dominant; In winter, the wind is mainly southerly and southwesterly. The probability of maximum wind speed greater than $6.0 \mathrm{~m} / \mathrm{s}$ is significantly higher than the other three ranges, but the probability is less than $25 \%$.

\section{Conclusions}

1) Precipitation is mainly concentrated in summer, followed by spring and autumn, and winter is the least; spatially, precipitation in spring, autumn and winter is mainly concentrated in Bomi area, Zuogong area is the least, summer is mainly concentrated in Litang area, Bomi area has the least precipitation. Rainstorms are most likely to occur in summer, and there is a high probability of no rain in autumn and winter $(>75 \%)$. According to the number of days and duration of rainstorms, Nyingchi and Bomi areas can be divided into low-prone areas, while Zuogong, Litang and Kangding areas can be classified as low-prone areas.

2) Using the percentage of precipitation anomaly as an indicator to construct flood indicators in line with the area along the Sichuan-Tibet Railway, and combined with NCL analysis to predict the storm and flood disasters along the Sichuan-Tibet Railway, the probability of flooding and drought disasters along the Sichuan-Tibet Railway can be analyzed.

3) The average temperature is on the rise. The average temperature in Linzhi area is higher, and the average temperature in Zuogong and Litang areas is lower. The probability of extreme high temperature events in the study area is very small. The high temperature period mainly occurs in the Bomi area, and the extreme low temperature event is most likely to occur in winter. The low temperature period is mainly concentrated in the Zuogong and Litang areas.

4) The average wind speed shows an increasing trend, with the highest average wind speed in spring, followed by winter, and similar and low in autumn and summer. Strong winds are most likely to occur in autumn and winter, but only $0.1 \%$ probability. The daily average wind speed in Zuogong area fluctuates greatly, and the daily average wind speed in Kangding area is relatively large. The probability of strong winds in these two areas is slightly higher than that in other areas.

5) The wind direction of the five regions is basically the same in all seasons, 
mainly controlled by easterly wind and southwesterly wind. From the time series analysis, it can be concluded that the winter wind speed is the largest in the study area, and from the time-space analysis, it can be concluded that the Kangding area has the largest wind speed in the four seasons.

\section{Acknowledgements}

Thanks for the data support provided by the National Climate Center for this study.

\section{Conflicts of Interest}

The authors declare no conflicts of interest.

\section{References}

[1] Malik, A.S., Boyko, O., Atkar, N. and Young, W.F. (2001) A Comparative Study of MR Imaging Profile of Titanium Pedicle Screws. Acta Radiologica, 42, 291-293. https://doi.org/10.1080/028418501127346846

[2] Xu, Z.X., Zhang, L.G., Jiang, L.W., Wang, K., Zhang, G.Z., Feng, T., Zhang, X.Y., et al. (2021) Engineering Geological Environment and Main Engineering Geological Problems of the Ya'an to Linzhi Section of the Sichuan-Tibet Railway. Engineering Science and Technology, No. 3, 29-42.

[3] Wang, M.R., et al. (2018) Coupling of the Quasi-Biweekly Oscillation of the Tibetan Plateau Summer Monsoon with the Arctic Oscillation. Geophysical Research Letters, 45, 7756-7764. https://doi.org/10.1029/2018GL077136

[4] Xun, X.Y., Hu, Z.Y., Sun, J., Cui, G.F., Xu, L.J. and Gu, L.L. (2011) Comparative Analysis of ECMWF and NCEP Reanalysis Data in the Changes in the Height Field of the Qinghai-Tibet Plateau. Glacier and Permafrost, No. 1, 80-87.

[5] Zhang, Z.Y. (2019) Analysis of Meteorological Risk Characteristics along the SichuanTibet Railway. Master's Thesis, Lanzhou University, Lanzhou.

https://kns.cnki.net/KCMS/detail/detail.aspx?dbname=CMFD201902\&filename $=10$ 19874222.nh

[6] Wu, G.X., He, B., Duan, A.M., Liu, Y.M. and Yu, W. (2017) Formation and Variation of the Atmospheric Heat Source over the Tibetan Plateau and Its Climate Effects. Advances in Atmospheric Sciences, 34, 1169-1184.

https://doi.org/10.1007/s00376-017-7014-5

[7] van der Geest, K. and van den Berg, R. (2021) Slow-Onset Events: A Review of the Evidence from the IPCC Special Reports on Land, Oceans and Cryosphere. Current Opinion in Environmental Sustainability, 50, 109-120. https://doi.org/10.1016/j.cosust.2021.03.008

[8] Sichuan News (2020) Sichuan-Tibet Railway Map. https://ss1.bdstatic.com/70cFvXSh Q1YnxGkpoWK1HF6hhy/it/u=2094997570,364 4044639\&fm $=26 \& g p=0 . j p g$

[9] Han, J., Cao, Y.C. and Zhang, F. (2017) Establishment of Pollution Weather Forecasting Ideas in Qingyang City. Chinese Agricultural Science Bulletin, No. 17, 102-107.

[10] Wang, Y.J., Shen, X.J. and Jiang, M. (2021) Temporal and Spatial Variation Characteristics of Different Grades of Precipitation in Changbai Mountain from 1961 to 2018. Climatic and Environmental Research, No. 2, 227-238.

[11] Xiong, J.N., Gong, Y., Liu, Z.Q., Fan, C.J. and Zhu, J.L. (2019) Forecast of Rains- 
torm and Flood in Tibet Based on Gray Theory. Glacier and Frozen Soil, No. 2, $457-$ 469.

[12] Mu, W.B., et al. (2014) The Copula function-Based Probability Characteristics Analysis on Seasonal Drought \& Flood Combination Events on the North China Plain. Atmosphere, 5, 847-869. https://doi.org/10.3390/atmos5040847

[13] Yuan, K.S., He, T.R., Wang, L.P. and Li, Z.G. (2021) Analysis on the Characteristics of the Temporal and Spatial Changes of Extreme Temperature in Xinjiang from 1971 to 2016. Xinjiang Environmental Protection, No. 1, 37-45.

[14] Zhang, Z.F., Zhang, H.P. and Ma, X.P. (2014) Variation Characteristics of Average Wind Speed and Strong Wind Days in Qaidam Basin. Arid Land Resources and Environment, No. 10, 90-94.

[15] Gao, Y., Li, B., Feng, Z. and Zuo, X. (2017) Global Climate Change and Geological Disaster Response Analysis. Chinese Journal of Geomechanics, No. 1, 65-77.

[16] Bian, J.H., Li, X.Z., Xu, R.C. and Wang, D. (2021) Hazardous Zoning of Large-Scale Landslides along the Sichuan-Tibet Railway Based on the Contribution Rate Weight Model. Chinese Journal of Geological Hazard and Control, No. 2, 84-93.

[17] Gao, H.X. and Yin, K.L. (2007). Correlation Analysis of Rainfall and Landslide Disasters and Discussion of Early Warning and Forecast Thresholds. Rock and Soil Mechanics, No. 5, 1055-1060. 